\title{
A Practical Look At Antenna And Propagation Requirements in Biotelemetry Systems For Fresh Water Fish
}

\author{
J. E. Lindsay, F. M. Long and R. W. Weeks \\ Department of Electrical Engineering \\ University of Wyoming \\ Laramie, Wyoming, 82071
}

\begin{abstract}
Propagation from a transmitter/antenna implanted in a fresh water fish is discussed. The choice of operating frequency based upon fish size, antenna efficiency and refraction effects is presented.

The implanted linear antenna is placed laterally along the fish. It is shown that for parallel polarization ( $\vec{E}$ in the plane of incidence) the wave, in air, has polarization dependent upon the elevation angle of the receiving antenna. For perpendicular polarization the polarization of the wave is always horizontal. Hence the polarization of the signal in the air depends upon the fishes position in the water. This leads to the conclusion that ground based receiving antennas should be circularly polarized so that either case can be handled.
\end{abstract}

For air-borne tracking, the major cone of reception places the aircraft at higher elevation angles and hence requires a horizontally polarized antenna. Since the fish can be at various azimuthal angles, a circularly polarized antenna placed beneath the aircraft is dictated.

The paper concludes with a discussion of an actual operating system as used by the U.S. Fish and Wildlife Service on the Truckee River.

Antenna and Propagation Considerations. The physical size of the fish will obviously determine the maximum allowable antenna size. For fresh water fish a practical size for the major dimension of a transmitter antenna package is around $10 \mathrm{~cm}$. To obtain reasonable efficiency in the transfer of power from the transmitter through the coupling network to the transmitter requires antenna dimensions on the order of a half wavelength. Fortunately the electrical wavelength in water is approximately one ninth that of free space. Based upon a major dimension of $10 \mathrm{~cm}$, a reasonable operating frequency would fall in the $150 \mathrm{MHz}$ range. Whether this frequency is acceptable will depend upon propagation losses in the water. Skin depth is a good measure of this loss and is of the order of a few meters in fresh water at these frequencies. Except for applications involving very deep lakes, this frequency range is an acceptable one. Conveniently the FCC has a band of frequencies at $164 \mathrm{MHz}$ assigned to wild life telemetry systems. 
Propagation from the water to the air must be considered. Assuming the fish-mounted antenna to be linearly polarized (horizontal relative to the air-water interface), then energy transmitted from the fish to a receiver depends upon the component of vector Ein the plane of incidence and the component perpendicular to this plane. Figures 1 and 2 show ray paths and the resulting polarization of $\vec{E}$ in the air for each of these cases. In water, incidence angles (relative to a normal at the interface) are restricted to about 6.4 degrees. For this range of incidence angles, the angle of the transmitted wave in air will fall between 0 and 90 degrees.

The power transmitted in air depends upon the two polarization cases and the angle of incidence. Power transmission, relative to unity for complete transmission, versus the angle in air is shown in Figure 3 for these two cases. For the parallel polarization case complete transmission takes place at the Brewsters angle. However, note that the signal (in air) is almost entirely vertically polarized. For the perpendicular polarization case the received signal remains horizontally polarized. Since the fish is generally at arbitrary azimuthal positions, both cases must be simultaneously considered. These properties result in the receiving antenna choices alluded to in the abstract.

A Typical Application. In order to help determine the migration patterns and spawning sites for Lahontan Cut Throat trout and Cui-ui sucker in the Truckee River between Pyramid Lake and Lake Tahoe, a radio tag was developed at the University of Wyoming. The keyer-transmitter was constructed using micro-circuit techniques. A folded half wavelength dipole was formed on a printed circuit board. The batteries and electronics were then mounted on the opposite side of this board. The dimensions are approximately 2 $\mathrm{x} 2 \mathrm{x} 10 \mathrm{~cm}$. The entire unit is hermetically sealed by an appropriate coating and placed on or within the fish.

These fish tags were used by the U.S. Fish and Wildlife Service (1) along that portion of the Truckee River mentioned above. This region constitutes a major logistics problem due to the length of the river and the difficulties of direct access to the river channel. The referenced report (1), describes a radio fish tracking system allowing accurate determination of the location of the spawning fish from a light aircraft.

\section{References.}

(1) R. W. Weeks, F. M. Long "Radio System for Fish Tracking on the Truckee River", April-June 1976 Quarterly Report to U.S. Fish and Wildlife Service. Contract \#SF WB103 638.

(2) E. C. Jorden, K. C. Balmain "Electromagnetic Waves and Radiating Systems" 2nd Ed. Prentice Hall, Inc. 1968. 


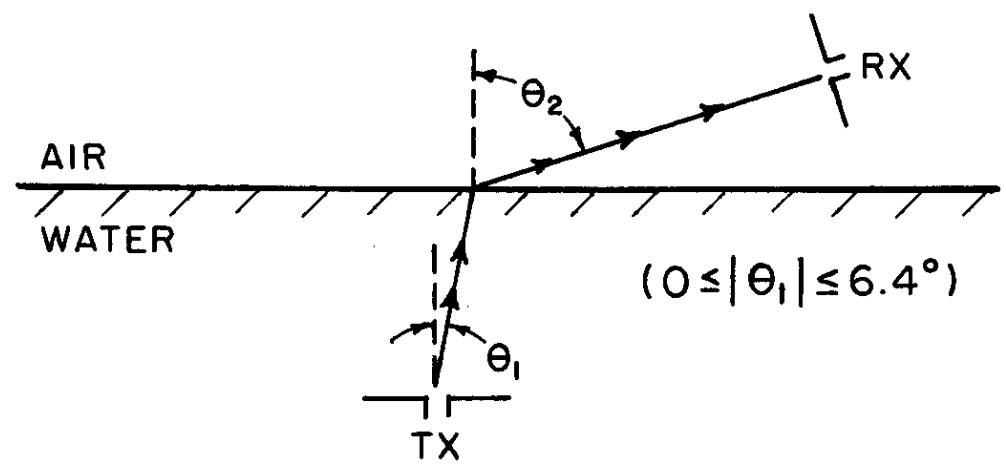

FIG. 1 RAY PATH FOR POLARIZATION PARALLEL TO THE PLANE OF INCIDENCE

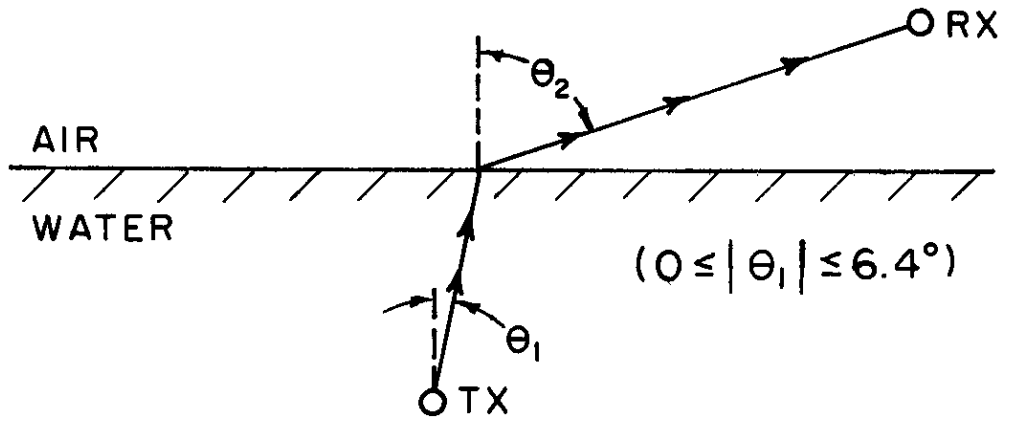

FIG. 2 RAY PATH FOR POLARIZATION PERPENDICULAR TO THE PLANE OF INCIDENCE

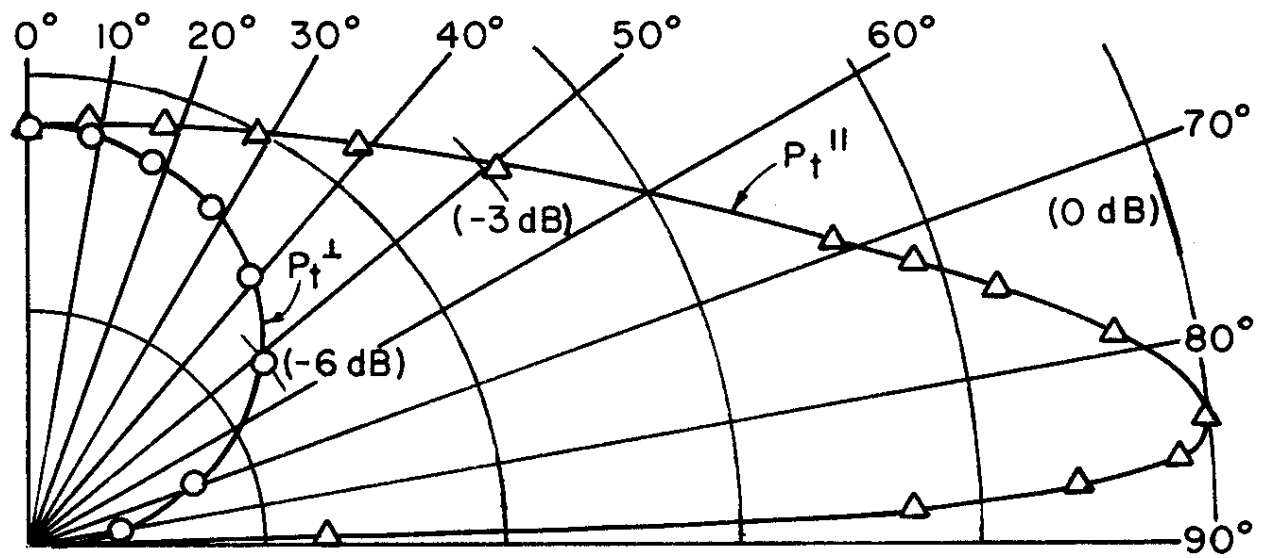

FIG. 3 RELATIVE POWER TRANSMITTED TO AIR REGION VS ELEVATION ANGLE FOR PERPENDICULAR AND PARALLEL POLARIZATION 